\title{
Pengembangan Instrumen Asesmen Berbasis Literasi Sains Tentang Materi Sistem Ekskresi dan Sistem Pernapasan
}

\author{
Helendra $^{1 *}$, D Ratna Sari ${ }^{2}$ (iD \\ 1,2 Universitas Negeri Padang, Padang, Indonesia \\ *Corresponding author: helendras@yahoo.com
}

\section{Abstrak}

Kurikulum 2013 yang berfokus pada peningkatan literasi sains, asesmen merupakan bagian integral dari proses pembelajaran sains. Namun berdasarkan hasill pengukuran yang dilakukan PISA (Programme for International Student Assessment), literasi sains Indonesia masih tergolong rendah. Tujuan penelitian ini adalah untuk menghasilkan instrumen asesmen berbasis literasi sains pada materi sistem ekskresi dan sistem pernapasan. Jenis penelitian ini adalah Research and Development dengan menggunakan model pengembangan Plomp yang terdiri dari tahap investigasi awal, tahap pengembangan atau tahap pembuatan prototipe, dan tahap penilaian. Subjek uji produk penelitian skala kecil adalah 9 orang siswa, dan uji coba lapangan adalah 32 orang siswa. Hasil penelitian menunjukkan rata-rata nilai validitas logis instrumen sebesar $87,23 \%$ dinyatakan sangat valid dan nilai validitas empiris sebesar $80,00 \%$. Hasil uji praktikalitas instrumen asesmen oleh guru memperoleh nilai $89,52 \%$ dan oleh siswa $88,43 \%$. Reliabilitas instrumen asesmen berbasis literasi sains menunjukkan kategori sangat tinggi dengan nilai reliabilitas 0,93 , terdapat $80 \%$ soal dengan kriteria tingkat kesukaran sedang, dan $66 \%$ soal dengan daya pembeda baik. Berdasarkan hasil penelitian, dapat disimpulkan bahwa instrumen asesmen berbasis literasi sains materi sistem ekskresi dan sistem pernapasan dapat dinyatakan sangat valid, sangat praktis, dan reliabilitas soal sangat tinggi.

Kata kunci: Asesmen, Literasi Sains

\section{Abstract}

The 2013 curriculum which focuses on improving scientific literacy, assessment is an integral part of the science learning process. However, based on the results of measurements carried out by PISA (Program for International Student Assessment), Indonesian scientific literacy is still relatively low. This study aims to produce an assessment instrument based on scientific literacy on the excretory system and respiratory system material. This research is Research and Development using the Plomp development model which consists of the initial investigation stage, the development stage or the prototyping stage, and the assessment stage. The subjects of the small-scale research product test were 9 students, and the field trial was 32 students. The results showed that the average value of the logical validity of the instrument was 87,23\% which was declared very valid and the empirical validity value was $80,00 \%$. The results of the practicality test of the assessment instrument by teachers scored $89,52 \%$ and by students $88,43 \%$. The reliability of the scientific literacy-based assessment instrument shows a very high category with a reliability value of 0,93, $80 \%$ questions with moderate difficulty criteria and 66,00\% questions with good discriminating power. So, it can be concluded that the scientific literacy-based assessment instrument for the excretory system and respiratory system material can be declared very valid, very practical, and the reliability of the questions is very high.

\section{INTRODUCTION}

Pemahaman sains yang meliputi pemahaman terhadap alam melalui penguasaan ilmu dasar sains seperti kimia, biologi, fisika serta pemahaman tentang hakikat sains sebagai suatu penyelidikan ilmiah menjadi fokus utama dalam kajian literasi sains (Andriani et al., 2018; Bashooir \& Supahar, 2018; Lestari \& Setyarsih, 2020; Mijaya et al., 2019). Literasi sains berkaitan dengan kemampuan siswa dalam memahami informasi, ilmu pengetahuan dan fakta yang ada dalam kehidupan sehari-hari. Literasi sains tidak hanya menitikberatkan pada pengetahuan sains, tetapi juga keterampilan sains. Aspek keterampilan literasi sains antara lain keterampilan proses sains, pengambilan keputusan dalam isu-isu sosial ditinjau dari segi sains (socio scientific issue) serta pemecahan masalahnya (Ardianto \& Rubini, 2016; Septiani

$\begin{array}{lll}\text { History: } & & \text { Publisher: Undiksha Press } \\ \text { Received } & : 11 \text { November } 2020 & \text { Licensed: This work is licensed under } \\ \text { Revised } & : 11 \text { Desember } 2020 & \text { a Creative Commons Attribution 3.0 License } \\ \text { Accepted } & : 26 \text { April } 2021 & \text { CC } \\ \text { Published } & : 25 \text { Mei } 2021 & \text { (C) }\end{array}$


et al., 2019; Yuliati, 2017). Aspek keterampilan literasi sains tersebut hendaknya dilatih kepada siswa dalam pembelajaran sains di kelas.

Namun, berdasarkan hasil observasi dan wawancara dengan 3 orang guru IPA dan 10 orang siswa, didapatkan informasi bahwa salah satu penyebab rendahnya literasi sains siswa yaitu belum tersedianya instrumen asesmen berbasis literasi sains di sekolah. Guru pernah menggunakan soal PISA, namun terbatas hanya pada saat uji coba. Sedangkan menurut siswa, mereka belum terbiasa menjawab soal dengan tipe soal PISA, dan pada soal berbasis literasi yang mereka kerjakan terlalu banyak soal sulit, sehingga sulit dijawab. Berdasarkan informasi tersebut, dilakukan analisis terhadap soal ujian yang digunakan dalam evaluasi belajar di sekolah. Hasil analisis menunjukkan bahwa instrumen asesmen tersebut belum sesuai dengan literasi sains berdasarkan PISA karena soal didominasi oleh tingkat kognitif rendah, dan soal yang digunakan belum berorientasi peningkatan literasi sains siswa. Hasil analisis berdasarkan kompetensi literasi sains pada soal yang digunakan menunjukkan bahwa soal didominasi oleh kompetensi menafsirkan data dan bukti ilmiah namun sangat rendah pada kompetensi menjelaskan fenomena ilmiah, dan mengevaluasi dan merancang penyelidikan ilmiah. Hal ini menyebabkan kemampuan bernalar siswa tidak terasah, sehingga lemah dalam menjawab soal yang berorientasi analisis dan pemecahan masalah.

Literasi sains merupakan unsur kecakapan hidup yang harus menjadi hasil kunci (key outcome) dari proses pendidikan hingga anak berusia 15 tahun. Dengan alasan itu, anak usia 15 tahun (menjelang akhir wajib belajar) dipandang perlu untuk memiliki tingkat literasi sains yang memadai, baik bagi yang akan melanjutkan studi dalam bidang sains maupun yang tidak (Khery et al., 2019; Tesi Muskania \& Wilujeng, 2017; Yuliati \& Saputra, 2019). Berdasarkan hasil studi pendahuluan tersebut, maka pengembangan instrumen asesmen berupa soal-soal berbasis literasi sains sangan perlu dikembangkan di sekolah. Baik sebagai bahan alat evaluasi dan acuan bagi guru dalam mengembangkan instrumen asesmen, maupun sebagai bahan latihan dalam menjawab soal literasi sains bagi siswa. Pengembangan instrumen tes berbasis PISA dapat melatih kemampuan penalaran menjadi meningkat (Septiani et al., 2019; Sinaga, 2015).

Beberapa penelitian relevan dengan penelitian ini seperti penelitian yang dilakukan oleh (Charmila et al., 2016) yang menemukan bahwa soal yang dikembangkan sesuai dengan PISA menjadikan siswa melibatkan berbagai kemampuan dasar matematika dan kemampuan berpikir kritis dalam penyelesaiannya. Kemudian penelitian yang dilakukan oleh (Lestari \& Setyarsih, 2020) menemukan bahwa sebanyak 16 butir soal (64\%) yang dikembangkan valid dan reliabel serta mampu mengukur dan memotret profil kemampuan literasi sains serta berpikir kritis peserta didik, sehingga layak untuk digunakan. Kemudian penelitian lain juga menemukan bahwa asesmen kinerja Literasi Sains berbasis STEM layak digunakan karena telah memenuhi syarat dalam aspek validitas isi, validitas empiris dan reliabilitas (Bashooir \& Supahar, 2018). Tujuan penelitian ini menghasilkan instrumen asesmen berbasis literasi sains tentang materi sistem ekskresi dan sistem pernapasan.

\section{MATERIALS AND METHODS}

Penelitian ini merupakan penelitian pengembangan (Research and Development), menggunakan model pengembangan Plomp yang terdiri dari tahap investigasi awal (preliminary research), tahap pengembangan atau tahap pembuatan prototipe (development or prototyping phase) dan tahap penilaian (assesment phase) (Plomp, McKenney \& Reeves, 2014). Tahap preliminary research meliputi analisis kurikulum, analisis kebutuhan, analisis siswa, dan analisis asesmen pembelajaran yang digunakan di sekolah. Tahap selanjutnya merupakan tahap perancangan, pembuatan dan pengembangan prototype. Pembuatan prototype berupa soal objektif, disesuaikan dengan standar literasi sains yang telah ditetapkan 
PISA. Selanjutnya pada tahap penilaian (assessment phase), dilakukan evaluasi formatif dengan beberapa tahapan, yaitu meliputi penilaian diri sendiri (self evaluation), penilaian pakar (expert review), penilaian satu-satu (one to one evaluation), penilaian oleh kelompok kecil (small group), dan uji lapangan (field test). Alur evaluasi formatif dalam penelitian ini dapat dilihat pada Gamabr 1.

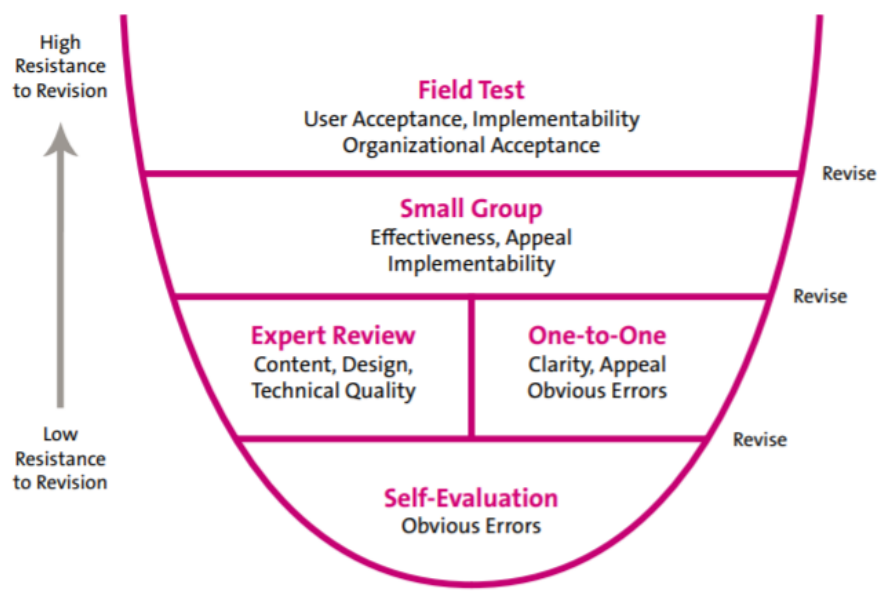

Gambar 1. Alur Evaluasi Formatif

Instrumen yang valid secara logis dari validasi expert review dan uji one to one diuji coba pada skala kecil dengan 9 siswa. Hasil uji coba skala kecil kemudian direvisi dan di uji coba skala luas. Uji coba skala luas dilakukan pada 32 orang siswa. Instrumen pengumpul data berupa angket wawancara, lembar analisis soal, lembar evaluasi diri sendiri (self evaluation), lembar validasi, lembar evaluasi uji satu-satu (one to one), angket praktikalitas guru dan siswa, serta lembar jawaban siswa. Data penelitian untuk validitas logis diukur menggunakan lembar validasi, sedangkan data praktikalitas diukur menggunakan lembar praktikalitas. Lembar tersebut diberi skor sesuai dengan skala Likert. Jenis data kualitatif dianalisis menggunakan teknik deskriptif kuantitatif. Validitas empiris instrumen dilakukan dengan menganalisis validitas item butir soal, yaitu membandingkan nilai $\mathrm{r}$ pada tiap butir soal dengan $\mathrm{r}$ product moment. Reliabilitas instrumen diukur menggunakan formula Kuder Richardson rumus $\mathrm{KR}_{20}$.

\section{RESULTS AND DISCUSSION}

Penelitian ini menghasilkan instrumen asesmen berbasis literasi sains yang terdiri dari 50 soal pilihan ganda dengan empat pilihan jawaban, yang menuntut siswa untuk berfikir kritis dalam memilih pilihan jawaban yang tersedia. Ketika siswa diberikan pertanyaan dalam bentuk tes pilihan ganda, siswa harus mengevaluasi setiap pilihan dan memilih satu jawaban yang paling sesuai. Soal ini terbagi kedalam 16 unit dan telah mendekati sebaran persentase literasi sains sesuai dengan framework PISA 2015 yang memuat aspek kompetensi, konteks aplikasi sains, dan pengetahuan sains. Selain itu, instrumen asesmen literasi sains yang dikembangkan dilengkapi dengan tingkat kognitif berdasarkan PISA (low, medium dan high).

Tingkat validitas soal diukur dengan mengunakan lembar validasi. Menetapkan validitas instrumen merupakan bagian penting dari proses pengembangan. Validitas menentukan sejauh mana instrumen mengukur apa yang dimaksudkan untuk diukur. Cara untuk menentukan validitas instrumen, adalah dengan fokus pada nilai validitas konten dan validitas konstruk (Gormally et al., 2012). Secara garis besar, terdapat 4 aspek yang dinilai dalam validasi instrumen asesmen berbasis literasi sains ini. Aspek-aspek tersebut meliputi 
aspek materi, konstruksi, bahasa/budaya, dan literasi sains. Hasil uji validitas logis dapat dilihat pada Tabel 1.

Tabel 1. Hasil Uji Validitas Logis Instrumen Asesmen Berbasis Literasi Sains

\begin{tabular}{clcc}
\hline No. & Aspek Penilaian & Nilai Validitas (\%) & Kategori \\
\hline 1. & Materi & $91,67 \%$ & Sangat valid \\
2. & Konstruksi & $92,50 \%$ & Sangat valid \\
3. & Bahasa/budaya & $75,00 \%$ & Valid \\
4. & Literasi sains & $89,74 \%$ & Sangat valid \\
\cline { 1 - 2 } \multicolumn{1}{r}{ Total } & $\mathbf{3 4 8 , 9 1 \%}$ & \multirow{2}{*}{ Sangat valid } \\
\hline
\end{tabular}

Hasil analisis data validitas logis menunjukkan bahwa instrumen asesmen berbasis literasi sains yang dikembangkan secara keseluruhan telah memenuhi kriteria sangat valid dengan rata-rata nilai validitas sebesar 87.23\%. Ditinjau dari aspek materi, instrumen asesmen berbasis literasi sains yang dikembangkan memiliki nilai validitas yaitu $91.67 \%$ dengan kriteria sangat valid. Hal ini menunjukkan bahwa soal yang dikembangkan sudah sesuai dengan kurikulum 2013, KI dan KD, serta indikator soal mewakili setiap aspek materi yang dipelajari oleh siswa. Surapranata (2007) menyatakan, bahwa materi yang hendak diukur harus sesuai dengan tuntutan kompetensi dasar dan indikator yang terdapat pada kurikulum. Kriteria valid untuk instrumen asesmen literasi sains juga menunjukkan bahwa materi yang ditanyakan sudah sesuai dengan kompetensi (urgensi, relevansi, kontinuitas, keterpakaian sehari-hari) yang ingin dicapai.

Ditinjau dari aspek konstruksi, nilai validitas yang diperoleh adalah sebesar $92.50 \%$ dengan kriteria sangat valid. Artinya, soal berbasis literasi sains yang dibuat sudah dirumuskan secara singkat, jelas, tegas, pilihan jawaban sudah homogen dan logis. Materi yang hendak diukur harus jelas, tidak menimbulkan penafsiran yang berbeda dari yang dimaksudkan penulis. Selain itu semua pilihan jawaban harus berasal dari materi yang sama seperti yang ditanyakan oleh pokok soal, penulisannya setara, dan semua pilihan jawaban harus berfungsi. Ditinjau dari aspek bahasa/budaya, nilai validitas yang diperoleh adalah sebesar $75.00 \%$ dengan kriteria valid. Hal ini berarti bahasa yang digunakan dalam instrumen asesmen ini telah sesuai dengan kaidah bahasa Indonesia yang baik dan benar, komunikatif, tidak bermakna ganda, mengunakan kata-kata umum, dan menggunakan tanda baca yang benar.

Ditinjau dari aspek literasi sains, instrumen asesmen berbasis literasi sains yang dikembangkan dinyatakan sangat valid oleh validator dengan nilai validitas yaitu $89.74 \%$. Yang menunjukkan bahwa instrumen asesmen yang dikembangkan telah memenuhi aspekaspek literasi sains berdasarkan framework PISA 2015, yaitu aspek konteks aplikasi sains, kompetensi, dan pengetahuan sains. Soal yang dibuat sudah dapat mengenal isu-isu secara ilmiah, menjelaskan fenomena ilmiah, dan menggunakan bukti ilmiah. Secara keseluruhan, hasil validasi ini menunjukkan bahwa instrumen sangat layak digunakan dalam proses evaluasi pembelajaran. Instrumen yang valid kemudian diujikan pada tahap evaluasi one to one dan small group untuk melihat gambaran awal respon siswa dan kemungkinan nilai praktikalitas. Pada tahap uji lapangan, instrumen asesmen diujikan kembali untuk mendapatkan nilai validitas empiris dan nilai praktikalitas. Hasil analisis praktikalitas oleh siswa dan guru dapat dilihat pada Tabel 2, Sedangkan hasil praktikalitas oleh guru dapat dilihat pada Tabel 3. 
Tabel 2. Hasil Analisis Uji Praktikalitas Instrumen oleh Siswa

\begin{tabular}{cccc}
\hline No. & Aspek Penilaian & Nilai Praktikalitas (\%) & Kriteria \\
\hline 1. & Petunjuk soal & $88,28 \%$ & Sangat praktis \\
2. & Kemudahan penggunaan & $88,51 \%$ & Sangat praktis \\
3. & Keefektifan waktu & $86,71 \%$ & Sangat praktis \\
4. & Ekuivalensi & $90,23 \%$ & Sangat praktis \\
\cline { 1 - 2 } & Total & $\mathbf{3 5 3 , 7 3 \%}$ & \multirow{2}{*}{ Sangat praktis } \\
\hline
\end{tabular}

Tabel 3. Hasil Analisis Uji Praktikalitas Instrumen oleh Guru

\begin{tabular}{clcc}
\hline No. & \multicolumn{1}{c}{ Aspek Penilaian } & Nilai Praktikalitas (\%) & Kriteria \\
\hline 1. & Petunjuk soal & $91,70 \%$ & Sangat praktis \\
2. & Kemudahan penggunaan & $90,70 \%$ & Sangat praktis \\
3. & Keefektifan waktu & $83,30 \%$ & Sangat praktis \\
4. & Pemeriksaan & $94,40 \%$ & Sangat praktis \\
5. & Ekuivalensi & $87,5 \%$ & Sangat praktis \\
\cline { 1 - 3 } & Total & $\mathbf{4 4 7 , 6 0 \%}$ & \multirow{2}{*}{ Sangat praktis } \\
\hline
\end{tabular}

Berdasarkan hasil analisis data uji praktikalitas oleh guru, didapatkan nilai praktikalitas sebesar $89.52 \%$ dengan kriteria sangat praktis dan praktikalitas oleh siswa sebesar $88.43 \%$ dengan kriteria sangat praktis. Nilai praktikalitas ini merupakan nilai ratarata dari beberapa aspek dalam lembar praktikalitas, yang mencakup aspek petunjuk soal yang telah berfungsi dengan baik, kemudahan penggunaan instrumen asesmen, keefektifan waktu pengerjaan instrumen asesmen, kemudahan pemeriksaan jawaban, serta ekuivalensi atau kesetaraannya dengan tuntutan kurikulum yang diterapkan di sekolah. Persentase tertinggi nilai praktikalitas oleh guru terdapat pada aspek pemeriksaan sebesar $94.40 \%$ dengan kriteria sangat praktis, sedangkan nilai tertinggi praktikalitas oleh siswa terdapat pada aspek ekuivalensi sebesar 90.23\%. Artinya instrumen asesmen berbasis literasi sains dibutuhkan siswa sebagai alat bantu atau sarana dalam latihan mengerjakan soal-soal yang membutuhkan analisis tingkat tinggi. Sedangkan bagi guru, soal memiliki kunci jawaban, pedoman penskoran, dan lembar jawaban, yang memudahkan guru dalam menggunakan instrumen dalam evaluasi. Tes yang praktis adalah tes yang mudah pemeriksaannya, artinya tes dilengkapi dengan kunci jawaban dan pedoman skoringnya.

Pada aspek petunjuk soal, guru memberikan nilai praktikalitas sebesar $91.70 \%$ dengan kriteria sangat praktis, dan praktikalitas oleh siswa sebesar $88.28 \%$, dengan kriteria sangat praktis. Hal ini berarti instrumen asesmen berbasis literasi sains dilengkapi petunjuk soal yang mudah dipahami dan berfungsi dengan baik sehingga tidak membuat siswa kebingungan. Petunjuk yang diberikan sebelum tes dimulai, akan memberikan ketenangan kepada siswa dalam mengerjakan tes, dan dalam penyelenggaraan tidak akan terdapat banyak pertanyaan. Aspek kemudahan dalam penggunaan instrumen ini memiliki nilai praktikalitas oleh guru sebesar $90.70 \%$ dengan kriteria sangat praktis, dan praktikalitas oleh siswa sebesar $88.51 \%$. Penilaian yang diberikan guru terhadap aspek kemudahan dalam menggunakan soal ini dikarenakan soal tidak harus memiliki keahlian khusus dalam penggunaannya. Soal mudah dipahami dan wacana yang terdapat pada soal ditampilkan dengan konteks yang dapat diaplikasikan dalam kehidupan sehari-hari.

Aspek keefektifan waktu pelaksanaan tes dinilai sangat praktis oleh guru dengan nilai $83.30 \%$ dan oleh siswa $86.71 \%$, dikarenakan soal yang diuji berjumlah 50 soal cukup untuk dikerjakan selama 120 menit. Hal ini menandakan instrumen asesmen berbasis literasi sains 
yang dikembangkan mendukung pelaksanaan tes yang efektif dan efisien. Penyusunan tes hendaknya disusun dengan mengalokasikan waktu. Sesuaikan waktu jam pelajaran dan perkiraan lamanya waktu yang dibutuhkan siswa untuk menyelesaikan semua soal. Aspek ekuivalensi berarti ada hubungan atau ekuivalen. Perolehan kriteria sangat praktis oleh guru sebesar $87.50 \%$, dan oleh siswa sebesar $90.23 \%$ artinya soal sudah memiliki kesetaraan dengan kurikulum yang berlaku di sekolah. Hal ini dikarenakan kurikulum yang mencakup silabus pembelajaran sudah menjadi acuan bagi penulis dalam merancang kisi-kisi instrumen asesmen. Nilai rerata hasil praktikalitas menunjukkan instrumen asesmen berbasis literasi sains sudah memenuhi kriteria praktikalitas yan tinggi. Perangkat pembelajaran yang memenuhi syarat sangat praktis, berarti bahwa semua komponen perangkat pembelajaran yang dikembangkan dalam penelitian ini layak untuk diimplementasikan dalam proses pembelajaran di kelas. Selanjutnya dilakukan uji validitas empiris dan analisis butir soal. Suatu tes dikatakan memiliki validitas empiris apabila telah diuji melalui pengalaman atau atas dasar pengamatan di lapangan. Validitas empiris diketahui dengan cara menganalisis butir soal yang telah diuji menggunakan rumus korelasi product moment. Sebuah soal dikatakan valid apabila koefisien dari korelasi product moment ( $\mathrm{r}$ hitung) yang diperoleh lebih besar $\mathrm{r}$ tabel (Uno, 2012). Hasil analisis butir soal pada instrumen asesmen yang dikembangkan dapat dilihat pada Tabel 4.

Tabel 4. Hasil Analisis Butir Soal pada Evaluasi Uji Lapangan (Field Test)

\begin{tabular}{ccll}
\hline $\begin{array}{c}\text { Validitas Empiris } \\
\text { (rentang nilai) }\end{array}$ & Reliabilitas & \multicolumn{1}{c}{$\begin{array}{c}\text { Tingkat Kesukaran } \\
(\boldsymbol{\%})\end{array}$} & \multicolumn{1}{c}{ Daya Pembeda (\%) } \\
\hline Valid $(0.27-0.71)$ & Reliabel $(0,93)$ & Sukar $(12,00 \%)$ & Jelek $(24,00 \%)$ \\
& & Sedang $(74,00 \%)$ & Cukup $(10,00 \%)$ \\
& & Mudah $(14,00 \%)$ & Baik $(52,00 \%)$ \\
& & Baik sekali $(14,00 \%)$ \\
\hline
\end{tabular}

Selain menganalisis jumlah soal yang valid secara empiris, penulis juga membandingkan persentase kompetensi literasi sains butir soal yang valid secara logis dan empiris. Hasil analisis kompetensi literasi sains soal dapat dilihat pada Tabel 5. Banyak faktor yang dapat mempengaruhi hasil tes evaluasi tidak valid. Berdasarkan sumbernya, terdapat faktor internal tes, fakor eksternal tes, dan faktor yang berasal dari siswa yang bersangkutan bisa mempengaruhi validitas suatu hasil tes evaluasi. Faktor internal tes pada penelitian ini adalah terdapat beberapa butir soal dengan tingkat kesukran sangat mudah, dengan demikian sebagian besar siswa menjawab benar sehingga nilai korelasinya sangat rendah, artinya nilai butir hamper tidak berpengaruh pada skor total. Faktor lain yang mempengaruhi nilai validitas instrumen evaluasi ini adalah suasana sekitar kelas yang kurang kondusif karena memakai sebagian waktu istirahat. Akibatnya konsentrasi siswa menjadi terpecah saat mengerjakan soal.

Nilai reliabilitas butir soal yang didapatkan untuk soal pilihan ganda yaitu 0.93 dengan kriteria sangat tinggi. Hal ini berarti bahwa instrumen asesmen berbasis literasi sains yang dikembangkan telah memiliki taraf ketetapan yang tinggi, yaitu kapanpun instrumen asesmen ini diujikan kepada siswa akan memberikan hasil yang relatif sama. Tes dikatakan reliabel apabila hasil tes tersebut menunjukkan ketetapan, dalam kata lain jika diberikan tes yang sama kepada siswa pada waktu yang berlainan, maka setiap siswa akan berada dalam urutan yang sama. Banyak faktor yang mempengaruhi hasil tes yang secara tidak langsung akan mempengaruhi reliabilitas soal tes. Semakin heterogen kemampuan peserta tes maka semakin tinggi reliabilitas tes. Semakin besar jumlah peserta tes maka semakin besar reliabilitas tes. Semakin sedikit jumlah item tes maka tidak akan reliabel karena tidak representatif. Tingkat kesukaran soal yang dikembangkan sudah bervariasi. Berdasarkan hasil 
analisis pilihan ganda diketahui sebanyak $6.00 \%$ soal yang tergolong sukar, $80.00 \%$ soal yang tergolong sedang, dan $14.00 \%$ soal yang tergolong mudah. Secara umum, tingkat kesukaran soal literasi sains berada pada tingkat sukar. Namun, instrumen asesmen yang dikembangkan berada pada kisaran soal sedang yaitu soal tidak terlalu mudah dan tidak terlalu sukar. Soal yang baik adalah soal yang tidak terlalu mudah atau tidak terlalu sukar (Inteni et al., 2013; Sari et al., 2016). Soal yang terlalu mudah menyebabkan siswa tidak mempertinggi usaha memecahkannya. Sebaliknya soal yang terlalu sukar menyebabkan siswa putus asa dan tidak mempunyai semangat untuk mencoba lagi.

Tabel 5. Analisis Kompetensi Literasi Sains Soal yang Valid secara Logis dan Empiris

\begin{tabular}{lllll}
\hline No. & \multicolumn{1}{c}{$\begin{array}{c}\text { Kompetensi } \\
\text { Literasi Sains }\end{array}$} & PISA (\%) & $\begin{array}{c}\text { Soal yang Valid } \\
\text { secara Logis (\%) }\end{array}$ & $\begin{array}{c}\text { Soal yang Valid } \\
\text { secara Empiris } \\
(\%)\end{array}$ \\
\hline $1 . \quad \begin{array}{l}\text { Menjelaskan fenomena } \\
\text { ilmiah }\end{array}$ & $40-50$ & $44,00 \%$ & $45,00 \% \%$ \\
2. & $\begin{array}{l}\text { Mengevaluasi dan } \\
\text { merancang } \\
\text { penyelidikan ilmiah } \\
\text { Menafsirkan data dan } \\
\text { bukti ilmiah }\end{array}$ & $20-30$ & $24,00 \%$ & $25,00 \%$ \\
3. $30-40$ & $32,00 \%$ & $30,00 \%$ \\
\hline
\end{tabular}

Instrumen asesmen berbasis literasi sains memiliki daya pembeda untuk pilihan ganda kriteria baik sekali $14.00 \%$, baik $52.00 \%$, cukup $10 \%$, dan jelek $24.00 \%$. Berdasarkan analisis daya pembeda, dapat dikatakan bahwa instrumen asesmen berbasis literasi dapat membedakan siswa yang memiliki kemampuan rendah dan kemampuan tinggi. Ada beberapa tindak lanjut atas hasil penganalisisan mengenai daya pembeda soal. Butir soal yang memiliki daya pembeda baik hendaknya dimasukkan dalam bank soal agar dapat digunakan pada tes yang akan datang. Butir soal yang memiliki daya pembeda rendah terdapat dua kemungkinan tindak lanjut, yaitu ditelusuri untuk kemudian diperbaiki, dan setelah diperbaiki dapat digunakan dalam tes yang akan datang, atau dibuang dan tidak akan dikeluarkan lagi (Abdullah et al., 2015; Agustika, 2018; Munandar et al., 2018; Zairmi et al., 2019). Butir soal yang memiliki indeks diskriminasi bertanda negatif sebaiknya pada tes yang akan datang tidak usah dikeluarkan lagi sebab kualitasnya jelek (testee yang termasuk pandai lebih banyak yang menjawab salah dibandingkan testee yang bodoh, yang justru hanya sedikit yang jawabannya salah).

Hasil penelitian ini didukung oleh hasil temuan penelitian yang dilakukan oleh (Charmila et al., 2016) yang menemukan bahwa soal yang dikembangkan sesuai dengan PISA menjadikan siswa melibatkan berbagai kemampuan dasar matematika dan kemampuan berpikir kritis dalam penyelesaiannya. Kemudian penelitian yang dilakukan oleh (Lestari \& Setyarsih, 2020) menemukan bahwa sebanyak 16 butir soal (64\%) yang dikembangkan valid dan reliabel serta mampu mengukur dan memotret profil kemampuan literasi sains serta berpikir kritis peserta didik, sehingga layak untuk digunakan. Kemudian penelitian lain juga menemukan bahwa asesmen kinerja Literasi Sains berbasis STEM layak digunakan karena telah memenuhi syarat dalam aspek validitas isi, validitas empiris dan reliabilitas (Bashooir \& Supahar, 2018). 


\section{CONCLUSION}

Instrumen asesmen berbasis literasi sains tentang sistem ekskresi dan sistem pernapasan dapat dinyatakan sangat valid, sangat praktis, dan reliabilitas soal sangat tinggi. Disarankan kepada guru agar mampu mengembangkan instrumen tes agar menunjang proses pembelajaran agar lebih baik ke depannya.

\section{REFERENCES}

Abdullah, D. I., Z, M., \& H, S. (2015). Keefektifan model pembelajaran problem based learning bernuansa etnomatematika terhadap kemampuan pemecahan masalah siswa kelas VIII. Unnes Journal of Mathematics Education., 4(3). https://doi.org/10.15294/ujme.v4i3.9056.

Agustika, G. N. S. (2018). Pengembangan konstruksi dan validasi tes konsep dasar Matematika. Journal of Education Technology, 2(1), 40-44. https://doi.org/10.23887/jet.v2i1.13805.

Andriani, N., Saparini, S., \& Akhsan, H. (2018). Kemampuan Literasi Sains Fisika Siswa SMP Kelas VII Di Sumatera Selatan Menggunakan Kerangka PISA (Program for International Student Assesment). Berkala Ilmiah Pendidikan Fisika, 6(3), 278-291. https://doi.org/10.20527/bipf.v6i3.5288.

Ardianto, D., \& Rubini, B. (2016). Literasi sains dan aktivitas siswa pada pembelajaran IPA terpadu tipe shared. USEJ - Unnes Science Education Journal, 5(1), 1167-1174. https://doi.org/10.15294/usej.v5i1.9650.

Bashooir, K., \& Supahar, S. (2018). Validitas dan reliabilitas instrumen asesmen kinerja literasi sains pelajaran Fisika berbasis STEM. Jurnal Penelitian Dan Evaluasi Pendidikan, 22(2), 168-181. https://doi.org/10.21831/pep.v22i2.20270.

Charmila, N., Zulkardi, Z., \& Darmawijoyo, D. (2016). Pengembangan Soal Matematika Model Pisa Menggunakan Konteks Jambi. Jurnal Penelitian Dan Evaluasi Pendidikan, 20(2), 198-207. https://doi.org/10.21831/pep.v20i2.7444.

Gormally, C., Brickman, P., \& Lut, M. (2012). Developing a test of scientific literacy skills (TOSLS): Measuring undergraduates' evaluation of scientific information and arguments. CBE Life Sciences Education, 11(4), 364-377. https://doi.org/10.1187/cbe.12-03-0026.

Inteni, K. A. S., Candiasa, I. M., \& Suarni, N. K. (2013). Pengembangan instrumen tes objektif pilihan ganda yang diperluas berbasis web untuk mata pelajaran TIK kelas XI SMAN di Kabupaten Karangasem. Jurnal Penelitian Dan Evaluasi Pendidikan, Vol 3(5). http://119.252.161.254/e-journal/index.php/jurnal_ep/article/view/1039/787.

Khery, Y., Nufida, B. A., Suryati, S., Rahayu, S., \& Aini, M. (2019). Pemahaman Mahasiswa tentang Hakikat Sains dalam Pembelajaran menggunakan Model Pembelajaran Mobile-NOS. Prisma Sains : Jurnal Pengkajian Ilmu Dan Pembelajaran Matematika Dan IPA IKIP Mataram, 7(2), 169-179. https://doi.org/10.33394/j-ps.v7i2.1771.

Lestari, D., \& Setyarsih, W. (2020). Kelayakan Instrumen Penilaian Formatif Berbasis Literasi Sains Peserta Didik Pada Materi Pemanasan Global. Ipf : Inovasi Pendidikan Fisika, 09(03), 561-570. https://doi.org/10.26740/ipf.v9n3.p561-570.

Mijaya, N. P. A. P., Sudiatmika, A. A. I. A. R., \& Selamet, K. (2019). Profil Literasi Sains Siswa Smp Melalui Model Pembelajaran Levels of Inquiry. Jurnal Pendidikan Dan $\begin{array}{llll}\text { Pembelajaran Sains } & \text { Indonesia } & \text { (JPPSI), } & 2(2),\end{array}$ https://doi.org/10.23887/jppsi.v2i2.19385.

Munandar, H., Sutrio, S., \& Taufik, M. (2018). Pengaruh model pembelajaran berbasis masalah berbantuan media animasi terhadap kemampuan berpikir kritis dan hasil belajar fisika siswa SMAN 5 Mataram tahun ajaran 2016/2017. Jurnal Pendidikan 
Fisika Dan Teknologi, 4(1), 111. https://doi.org/10.29303/jpft.v4i1.526.

Plomp, McKenney, S., \& Reeves, T. C. (2014). Educational design research. Handbook of Research on Educational Communications and Technology: Fourth Edition, January 2013, 131-140. https://doi.org/10.1007/978-1-4614-3185-5_11.

Sari, A. N., Wahyuni, R., \& Rosmaiyadi, R. (2016). Penerapan Pendekatan Open-Ended untuk Meningkatkan Kemampuan Berpikir Kritis Siswa Pada Materi Aljabar Kelas VIII SMP Negeri 10 Pemangkat. JPMI (Jurnal Pendidikan Matematika Indonesia), 1(1), 20. https://doi.org/10.26737/jpmi.v1i1.78.

Septiani, D., Widiyawati, Y., \& Nurwahidah, I. (2019). Pengembangan Instrumen Tes Literasi Sains Berbasis Pisa Pada Aspek Menjelaskan Fenomena Ilmiah Untuk Siswa Kelas Vii. Science Education and Application Journal, 1(2), 46. https://doi.org/10.30736/seaj.v1i2.144.

Sinaga, T. N. (2015). Pengembangan Soal Model Pisa Mata Pelajaran Ilmu Mengetahui Penalaran Siswa Kelas Ix. Jurnal Inovasi Dan Pembelajaran Fisika, 2(2), 194-197.

Tesi Muskania, R., \& Wilujeng, I. (2017). Pengembangan perangkat pembelajaran ProjectBased Learning untuk membekali foundational knowledge dan meningkatkan scientific literacy. Jurnal Cakrawala Pendidikan, 36(1), 34-43. https://doi.org/10.21831/cp.v36i1.8830.

Yuliati, Y. (2017). Literasi Sains Dalam Pembelajaran Ipa. Jurnal Cakrawala Pendas, 3(2), 21-28. https://doi.org/10.31949/jcp.v3i2.592.

Yuliati, Y., \& Saputra, D. S. (2019). Pembelajaran Sains Di Era Revolusi Industri 4.0. Jurnal Cakrawala Pendas, 5(2), 167-171. https://doi.org/10.31949/jcp.v5i2.1389.

Zairmi, U., Fitria, Y., \& Amini, R. (2019). Penggunaan Model Pembelajaran Two Stay Two Stray Dalam Pembelajaran IPA Di Sekolah Dasar. Jurnal Basicedu, 3(4), 1031-1037. https://doi.org/10.31004/basicedu.v3i4.221. 